\title{
Book Review : Shu-mei Shih and Lin-chin Tsai (Eds.), Indigenous Knowledge in Taiwan and Beyond
}

Gao, I-An

2021-09

Gao , I-A 2021 , ' Book Review : Shu-mei Shih and Lin-chin Tsai (Eds.), Indigenous Knowledge in Taiwan and Beyond ', AlterNative: An International Journal of Indigenous Peoples, vol. 17 , no. 3 , pp. 444-445 . https://doi.org/10.1177/11771801211037893

http://hdl.handle.net/10138/335309

https://doi.org/10.1177/11771801211037893

acceptedVersion

Downloaded from Helda, University of Helsinki institutional repository.

This is an electronic reprint of the original article.

This reprint may differ from the original in pagination and typographic detail.

Please cite the original version. 


\section{Shu-mei Shih and Lin-chin Tsai (eds.), Indigenous Knowledge in Taiwan and Beyond}

Indigenous Knowledge in Taiwan and Beyond is a collected edition which includes 15 articles written by leading Indigenous and non-Indigenous scholars in Taiwan, as well as scholars of Indigenous studies from outside Taiwan. Edited by Shu-mei Shih and Lin-chin Tsai, Indigenous Knowledge in Taiwan and Beyond is one of the first volumes on Indigenous knowledge in Taiwan to be published in English. The contributing authors write back against the dominant Han-Chinese and Japanese settler colonial framework while remaining cognizant of their commitment to uphold the sovereignty and knowledge of Indigenous Peoples, among others, 'Amis, Bunun, Cou, Paiwan, Seejiq, Siraya, Tayal and Truku. Drawing strength from a multitude ways of knowing from the Indigenous Peoples of Turtle Island, Australia, and Aotearoa New Zealand, this book marks a great stride of indigenizing research in Taiwan, and demonstrates how research plays a role in answering our needs and priorities as Indigenous Peoples.

The volume has two introductions and is divided into four sections. The first introduction contextualizes Indigenous Peoples and their ways of knowing and being in the literature of critical settler colonial and decolonial studies. The second introduction explains the structure of the book. Five articles concerning Indigenous knowledge, education and research ethics comprise the first section. The second section contains five articles pertaining to diverse forms of Indigenous cultural practices and land-based knowledge systems embedded in these practices. The penultimate section has five articles addressing an intersection of Indigenous studies, settler colonial studies and Latin American decolonial studies. The fourth section is 
Paiwan writer Ibau Dadelavan's reflection on her root-searching journey and her negotiation of indigeneity.

Written primarily by Indigenous authors in Taiwan, the articles in the first section reflect the diverse trajectory of Indigenous-state relations, including struggle for recognition in mainstream education, advocacy of Indigenous cosmology and pedagogy, the pursuit of sovereignty through visual activism, substantial ethics when engaging with Indigenous communities. Each of the five articles touches upon aspects of indigenization. Bunun scholar Tunkan Tansikian, known professionally by his Mandarin Chinese name Pei-lun Chen Chang, commences with the most complex and contentious aspect of indigenization, namely how Indigenous knowledge in Taiwan can be addressed in school curriculum. Advocating for an Indigenous education system independent from the dominant Han-Chinese system, Tansikian calls for more research in Indigenous knowledge and government's substantive support for Indigenous experimental education. In kuba-hosa-hupa: A preliminary exploration of Taiwan Indigenous Cou Cosmology and Pedagogy, Cou scholar tibusungu'e vayayana, also known by the name Ming-huey Wang, unpacks Cou concepts of holistic education and argues that the "contemporary Westernization and modernization school education systems actually cut off the organic connection between Cou people and their living world, ... and gradually confining humanity into the metropolitan space and capitalist merchandise instead of the natural environment" (p. 51). In The Making of Indigenous Knowledge in Contemporary Taiwan: A Case Study of Three Indigenous Documentary Filmmakers, Seejiq scholar Skaya Siku examines Indigenous knowledge from three Indigenous filmmakers' visual activism. 
How about ethical engagement with the communities? Siraya scholar Jolan Hsieh and 'Amis scholar Sifo Lakaw have addressed this question together with Ena Chang, in From Collective Consent to Consultation Platform: An experience of Indigenous research ethics in Makota'ay. Drawing from Kaupapa Māori (Māori Way; Māori principles) and consultation policy at the University of Arizona, the authors' effort to go outside the box of clicking-thebox ethics to holistic Indigenous sovereignty is immensely important. The thematic kernel ends with Cheng-feng Shih's Indigenous knowledge production and research ethics. In examining the strategies of regulations when conducting research in order to produce Indigenous knowledge, Shih proposes a comparative perspective and argues for full participation and consultation among stakeholders throughout the research process.

In the second section, the articles present analyses of diverse forms of Indigenous knowledge. The selection includes the role that millet played in 'Amis, Bunun, Paiwan and Rukai myths and rituals; ritual crops and agro-cultural complex for the Indigenous Ifugao in the Philippines and the Tayal in Taiwan; hunting and the role of Truku gaya (law; taboos); ecorealist stories of Indigenous hunting that challenge capitalist logic; and Bunun activism in reclaiming their embodied knowledge. Settler colonial studies and Latin American decolonial studies were brought into discussion in the third section vis-à-vis Indigenous studies. The fourth section shows the book's commitment to the non-linear, fluid and relational aspects of Indigenous knowledge by including Paiwan author Ibau Dadelavan's poetic writing on her constantly negotiating her identity among the worlds of academic research, literary writing, and Paiwan tradition and spirituality. Using eagle feathers as the main imagery, Dadelavan retains a melancholic tone when she reflects, "Experiences have revealed to me what a heavy burden my skin color and identity is. I can no longer carry my traditions and my culture with me ...(...) I must shave off the odor of my body and my original color to adapt to different 
views and values in order not to be wounded all over. Since many years ago, I removed the eagle feathers from my body. I do not want to be an alien." (p. 348) This reflection on indigeneity from 2004 in which she published her essay is posed as an invitation for a continuous dialogue for Indigenous Peoples' knowledges in Taiwan and beyond.

Indigenous Knowledge in Taiwan and Beyond is a collection of well-written articles by a group of devoted authors who sees both the Indigenous and the Dominant world with crystal clarity. It is ground-breaking as it eloquently points out the sovereignty of Indigenous Peoples and that Taiwan is inextricably embedded in their ongoing colonialism.

The community of Indigenous Peoples in Taiwan can be congratulated on having eloquent writers who contribute to furthering Indigenous-based research paradigm. Indigenous Knowledge in Taiwan and Beyond is a profound and empowering contribution to the decolonization priorities and aspirations of the Indigenous Peoples in Taiwan.

\section{Glossary}

'Amis

an Indigenous Peoples in Taiwan; largest Indigenous

population numbering 216,039 (2021); 37.3\% of Taiwan's total Indigenous population

Bunun an Indigenous People in Taiwan;

Cou an Indigenous People in Taiwan;

gaya Indigenous law; taboos 
Ifugao

an Indigenous People of the Ifugao mountain province, Philippines

Kaupapa Māori

Māori Way; Māori Principles, Philosophies and Praxis

Paiwan

an Indigenous People in Taiwan; second largest Indigenous

population numbering 104,112 (2021); 17.9\% of Taiwan's total Indigenous population

Rukai

an Indigenous People in Taiwan;

Seejiq an Indigenous Peoples in Taiwan; by the 2000s, the collective spelling of Sediq Toda /Seediq Tgdaya/Seejiq Truku (3S3T) is preferred by themselves and widely adopted

Siraya an Indigenous People in Taiwan; not yet officially recognized by the ROC government on the national level

Tayal an Indigenous People in Taiwan; third largest Indigenous population numbering 93,191 (2021); 16.1\% of Taiwan's total Indigenous population Truku an Indigenous People in Taiwan; 